\title{
Impact on Development of ZnS Nanoparticles Thin Film Deposited by Chemical Bath Deposition and Spin Coating
}

\author{
Noor Azie Azura Mohd Arif, Chin Suk Fun
}

\begin{abstract}
Research comparing the advantages of spin coating and chemical bath deposition is going, and there are varied views on these methods. Here, we used spin coating and chemical bath deposition to prepare thin films of $\mathrm{ZnS}$ nanoparticles. The film was analysed by photoluminescence $(P L)$ spectrophotometry, field emission scanning electron microscopy (FE-SEM), ultraviolet spectroscopy (UV-Vis), and energy-dispersive $X$-ray (EDX) spectroscopy. The UV-Vis spectra revealed that the wavelength of $\mathrm{ZnS}$ is between $220 \mathrm{~nm}-320 \mathrm{~nm}$ while the PL spectra showed a peak centred in the blue region. Both spin coating and chemical bath deposition rendered spherical nanoparticles but of different sizes $17.9 \mathrm{~nm}$ and $21.2-25.7 \mathrm{~nm}$, respectively. It was concluded that each method has its potential. This work can help researchers choose a suitable method for fabricating thin films, depending on the aims and objectives of their work.
\end{abstract}

Keywords: nanoparticles thin film, chemical bath deposition, spin coating

\section{INTRODUCTION}

The deposition of thin films of nanoparticles on substrates using diverse methods is still a topic of interest among researchers. Typically, $\mathrm{ZnS}$ thin films are synthesized by methods such as thermal evaporation [1], spray pyrolysis $[2,3]$, sputtering $[4,5,6]$, pulsed laser deposition [7, 8], chemical vapor deposition $[9,10]$, successive ionic layer adsorption and reaction (SILAR) [11], chemical bath deposition [12, 13, 14, 15, 16], chemical deposition [17], chemical precipitation $[18,19,20]$, spin coating $[21,22,23$, $24,25,26]$, dip coating $[22,28,29,30]$, green synthesis [31, $32,33,34]$, electro-deposition [35], and thermolysis [36, 37, $38,39,40]$. Each method has its advantages based on the aim of the study. Researchers widely favour the methods of spin coating and chemical bath deposition due to their simplicity as compared to other processes. Chemical bath deposition has a greater commercial value than either thermal evaporation or sputtering and has recently attracted the attention of researchers due to its simplicity, convenience, reproducibility, large-area scaling, and suitability for commercial-scale production [41]. Nabachandra et al. [42]

Manuscript received on February 03, 2021.

Revised Manuscript received on February 02, 2021.

Manuscript published on February 28, 2021.

* Correspondence Author

Noor Azie Azura Mohd Arif*, Centre for Pre-University Studies, Universiti Malaysia Sarawak, 94300 Kota Samarahan, Sarawak, Maalaysia. Email: manaazura@unimas.my

Chin Suk Fun, Faculty of Resource Science and Technology, Universiti Malaysia Sarawak, 94300 Kota Samarahan, Sarawak, Malaysia. Email: sfchin@unimas.my

(c) The Authors. Published by Blue Eyes Intelligence Engineering and Sciences Publication (BEIESP). This is an open access article under the CC BY-NC-ND license (http://creativecommons.org/licenses/by-nc-nd/4.0/) mentioned that the chemical bath deposition method is employed because of its advantages like low cost, low deposition temperature, and easy coating of smooth and uniform layers on large surfaces. This method is also attractive for modelling studies. Kostoglou et al. [43] developed a model for the fabrication of CdS thin films using chemical bath deposition. They tried to develop and optimise model equations based on a population balance formulation. Notably, the chemical bath deposition method was first used in 1946 to prepare PbS films for infrared applications. It is currently used to obtain semiconductor films on a large-scale. Essentially, a thin film deposition process involves three steps: (i) creation of atomic/molecular/ionic species, (ii) transport of these species through a medium, and (iii) condensation of the species. The basic principle involved in the synthesis of thin films by the chemical bath deposition method is the controlled precipitation of the desired compound from a solution of its constituents [41]. Spin coating and its allied process dip coating are well-known methods that are less expensive and less complicated. Spin coating is a process in which a flat surface is coated by a thin film of a liquid aided by the fast rotation of the surface. A spin coater is essentially a turntable maintained under vacuum conditions or mechanical parts. A liquid is deposited at the centre of the substrate which is placed on the turntable This is followed by a high-speed rotation (thousands of rotations per minute) of the turntable. The liquid spreads outwards to the edge of the substrate and forms a thin film of relatively uniform thickness. Some researchers have modified this technique by combining it with the self-assembly approach. Arif et al. [44] used metal tape as a barrier during the spinning process to prevent the solution from spreading outwards from the glass substrate. The thickness of the coating layer depends on the fluids viscosity, fluid density, angular velocity of the turntable, and the total time for which the sample is rotated [45]. Therefore, it is essential to understand the effects of various control variables on the thickness and uniformity of the thin film, since semiconductor devices require smooth and uniform photoresist films of predictable and reproducible thickness.

\section{METHODOLOGY}

In this study, a thin film of $\mathrm{ZnS}$ nanoparticles were prepared using the spin coating and chemical bath deposition methods. We aimed to analyse the characteristics of the films prepared by these two methods.

Published By:

Blue Eyes Intelligence Engineering and Sciences Publication

(C) Copyright: All rights reserved.

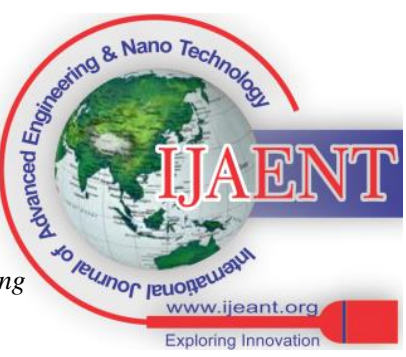




\section{Impact on Development of ZnS Nanoparticles Thin Film Deposited by Chemical Bath Deposition and Spin Coating}

First, a ZnS solution was produced via the sol-gel technique. Sol-gel technique was chosen because of its many advantages such as ease in the control of the film composition, and cost-effective and easy fabrication of large-area films [41]. The clear solution was prepared using dehydrated zinc acetate (ZAD), thiourea, ethanol, distilled water. A clear solution was obtained after $48 \mathrm{~h}$ of stirring. For the spin coating method, the $\mathrm{ZnS}$ sol was deposited on a glass substrate using a spin coater. The sample was rotated with high efficiency at a speed of $2000 \mathrm{rpm}$ for 20 s. For the chemical bath deposition process, the $\mathrm{ZnS}$ sol was deposited onto a glass slide and exposed to air for 15 mins. Both samples were annealed at $500^{\circ} \mathrm{C}$ to reduce material defects. The thin films were then cooled to room temperature $\left(23.7^{\circ} \mathrm{C}-32.7^{\circ} \mathrm{C}\right)$. The experiments were initially performed using chemicals that have been provided to produce $\mathrm{ZnS}$ nanoparticles thin film via two methods. Optical characterisation of the samples was carried out using UV-Visible spectroscopy (LAMBDA 950 Perkin Elmer), and photoluminescence spectrophotometry (FLSP920 Edinburgh Instruments). In contrast, the structural and compositional analysis of films was carried out via X-ray diffraction (D8 Advance Bruker), field emission scanning electron microscopy and energy-dispersive X-ray spectroscopy (Supra 55Vp).

\section{RESULTS AND DISCUSSION}

\section{A. Perspectives on FE-SEM images and EDX spectra}

FE-SEM images were obtained for the ZnS thin films deposited on glass substrates in order to study the surface of the thin films, especially their size and pattern. FE-SEM images for both $\mathrm{ZnS}$ thin films show that the nanoparticles The spin coating method produced a smaller size of nanoparticles $(17.9 \mathrm{~nm})$ as compared to the chemical bath deposition method (21.2 nm - $25.7 \mathrm{~nm})$. It is expected that the spin coating method will produce a smaller size because of the high speed (2000 rpm) and duration (20 s) of the spinning process. During this process, the particles get distributed rapidly and do not have much time to adhere to the glass substrate. The FE-SEM image for the thin film prepared with the chemical bath deposition method was clear due to the larger size of the nanoparticles as compared to the spin coating method. End side of a thin film for both methods proved the occurrence of nanoparticles on a glass substrate. A single thin layer can be seen clearly in Fig. 1(a) with a film thickness of $15.63 \mathrm{~nm}$. The chemical bath deposition method rendered multiple layers of the film with a good arrangement of the nanoparticles; moreover, the film was devoid of the bulk component. This method helped to perfectly create a deposition process. The film was deposited on to the glass slide within $15 \mathrm{~min}$; previous studies mention that the duration of deposition can affect the outcome of the thin films. A slight increase in the grain size follows from the increase of the deposition time but does not impact the surface roughness [46]. EDX analysis for both methods confirmed the presence of zinc (Zn) and sulphur (S) in ZnS, the spectra of which are shown in Fig. 2. The proportion of ethylenediaminetetraacetic (EDTA) as a surfactant and are approximately spherical with a slight difference in size. uniform layer which can be attributed to the duration of the

constituent elements measured for the spin coating and chemical bath deposition processes was $\mathrm{Zn}=80.6 \%$, 80.5\% and $\mathrm{S}=19.4 \%, 19.5 \%$ respectively.

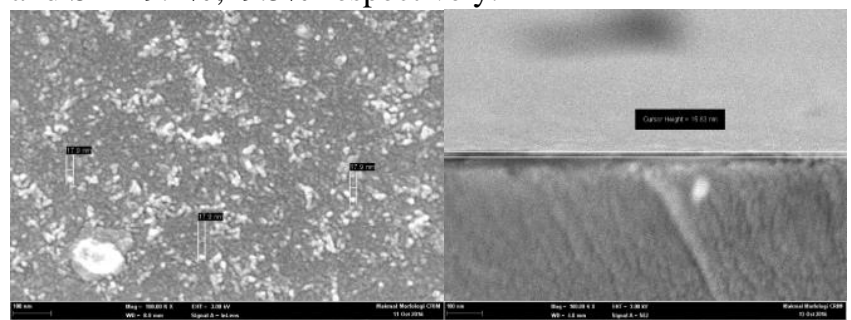

(a)

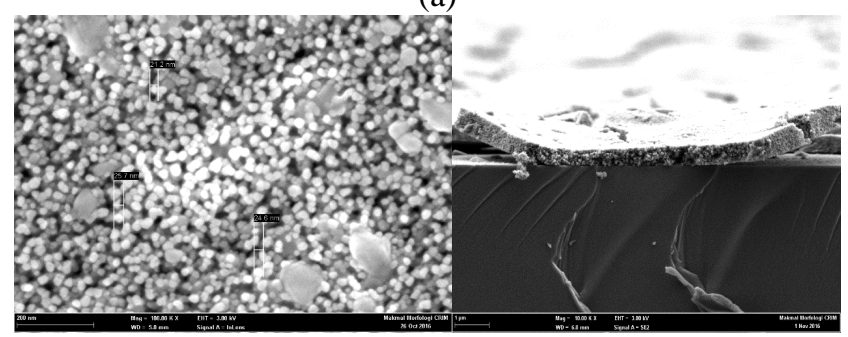

(b)

Fig. 1.Nanocrystalline thin film produced at the heating temperature $500{ }^{\circ} \mathrm{C}$ using (a) spin coating (b) chemical bath deposition method

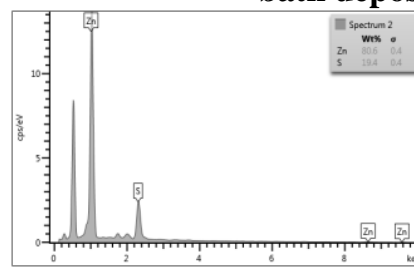

(a)

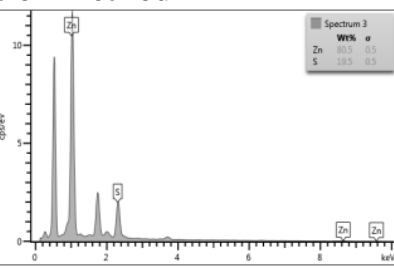

(b)
Fig. 2. EDX spectra (a) spin coating method (b) chemical bath deposition method

\section{B. Perspectives on Photoluminescent (PL) spectra}

Photoluminescent spectra for the $\mathrm{Zn}: \mathrm{S}$ ratio of (1:1 and 1:3) with the concentration factor can be seen in Fig. 3. A comparison of the PL and UV spectra reveals that both spectra present the same results. All thin films were excited at $250 \mathrm{~nm}$, but different factors led to the emission of wavelengths corresponding to different colours. The $\mathrm{Zn}: \mathrm{S}$ ratio exhibited two emission peaks at $390 \mathrm{~nm}$ and $450 \mathrm{~nm}$, while the concentration factor exhibited three emission peaks at $440 \mathrm{~nm}, 450 \mathrm{~nm}$ and $470 \mathrm{~nm}$. The broad and robust peak observed at $390 \mathrm{~nm}$ is attributed to the near-band-edge emission of ZnS. The emission at $440 \mathrm{~nm}, 450 \mathrm{~nm}$ and 470 $\mathrm{nm}$ can be attributed to the recombination of electrons at the surface sulphur vacancy with the holes at the valance band $[18,21,47]$. The recombination process is evident from the electrons trapped in the energy gap of ZnS. The impact of spin coating and chemical bath deposition impact are seen to be focused on the $\mathrm{Zn}: \mathrm{S}$ ratio. The sample prepared by the chemical bath deposition method exhibited a more substantial peak than that prepared by the spin coating method; this is evident from the spectra and correlates well with the results obtained from the FE-SEM images.

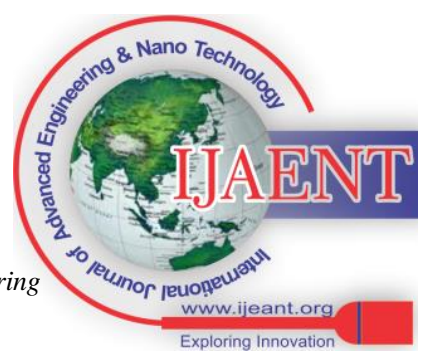


As seen in Fig. 1(b), the chemical bath deposition method rendered a larger size of $\mathrm{ZnS}$ nanoparticles. Hence, the nanoparticles could absorb more energy and exhibited more intensity of emission. In other words, the broadening of the emission peak can be attributed to the size distribution and increase in the surface states owing to the increase in the surface to volume ratio of the nanoparticles [48].

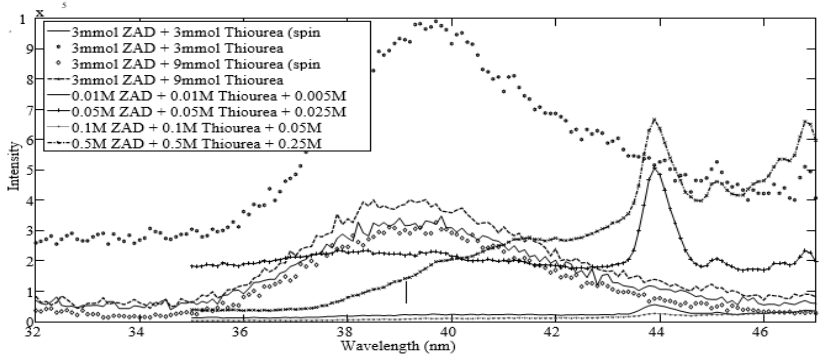

Fig. 3. Photoluminescence spectra of $\mathrm{ZnS}$ nanocrystals at different method, a ratio of $\mathrm{Zn}$ to $\mathrm{S}$ and concentration.

\section{Perspectives on the Absorption spectrum}

The optical properties of the $\mathrm{ZnS}$ nanoparticles can be interpreted from the absorption spectra shown in Fig. 4, wherein clear peaks can be seen within the range of 220-320 $\mathrm{nm}$. The six samples which were analysed showed different broadening wavelengths. The $\mathrm{Zn}: \mathrm{S}$ ratios of $1: 1$ and $1: 3$ also had an impact on the absorption characteristics; the absorption was higher for a more excellent ratio. This phenomenon is similar to that observed for the concentration factor. Regarding Fig. 4, the concentration influenced the outcome of the absorption region, with a greater concentration rendering a broader absorption peak in a higher wavelength region. A shift in the optical absorption spectrum is known to take place due to the quantum confinement effect, which occurs in the case of nanoparticles when the particle size becomes comparable with or smaller than the Bohr radius of an exciton [18]. Generally, a higher concentration would produce a larger size of particles; the same goes for the ratio of $\mathrm{Zn}$ to $\mathrm{S}$. However, the resulting spectrum shows a blue shift which is different from that observed for bulk ZnS [21].

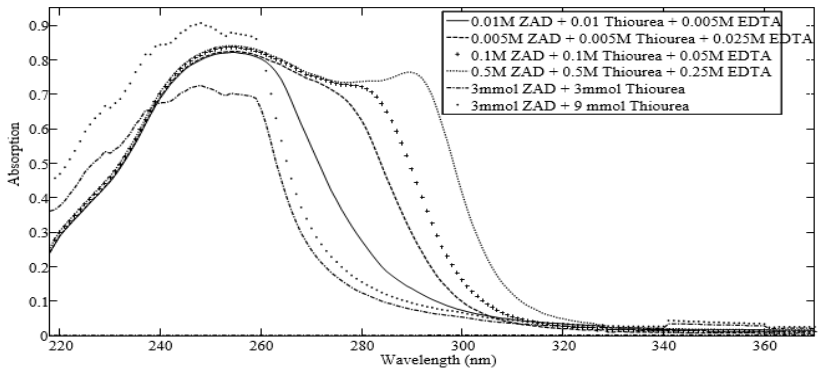

Fig. 4. UV-Visible absorption spectra of ZnS solutions

\section{CONCLUSION}

In the present work, thin films of spherical ZnS nanoparticles were prepared via the conventional methods of spin coating and chemical bath deposition. The XRD patterns indicate the presence of thiourea, zinc sulphide and zinc oxide. The PL spectra exhibited a blue emission, while the absorption edge appears in the range of $220 \mathrm{~nm}-320 \mathrm{~nm}$. The chemical bath deposition method rendered a larger size of nanoparticles, and the samples exhibited more excellent absorption and emission of energy than those prepared by the spin coating method. This conventional process is a simple, well-known, and beneficial method to synthesises thin films of semiconductor nanoparticles. This work can help researchers choose a suitable method to fabricate thin films in future based on structural mainly.

\section{ACKNOWLEDGMENT}

This work was supported by the Ministry of Higher Education (RAGS/SG01(1)/1310/2015(04), which is gratefully acknowledged. The researcher also thanks Center for Research and Instrumentation (CRIM), Universiti Kebangsaan Malaysia for analysis work, Physics Laboratory and Chemistry Laboratory, Centre for Pre-University Studies, Universiti Malaysia Sarawak for laboratory works.

\section{REFERENCES}

1. G. Sandhya, S. Kananbala, and N. S. Saxena, "Temperature Dependent Mechanical Analysis of Chalcogenide (CdS, ZnS) Coated PET Films,' ISRN Polymer Science 2013, Article ID 952612,

2. M. H. Suhail, and R. A. Ahmed, "Structural, Optical and Electrical Properties of Lead Doped Zinc Sulphide Thin Films Prepared by Chemical Spray Pyrolysis Technique," International Journal of Information Technology 2014; 2(9):11-17.

3. M. C. López, J. P. Espinos, F. Martín, D. Leinen, and J. R. Ramos-Barrado, "Growth of ZnS thin films obtained by chemical spray pyrolysis: The influence of precursors," In Journal of Crystal Growth 2005; 285(1-2): 66-75.

4. X. Hang, W. Lili, and W. Wenwu, "The Influence of Hydrogen on the Properties of Zinc Sulfide Thin Films Deposited by Magnetron Sputtering," International Journal of Photoenergy 2014, Article ID 720560, doi:10.1155/2014/720560

5. J. P. Zhang, G. He, L. Q. Zhu, M. Liu, S. S. Pan, and L. D. Zhang, "Effect of oxygen partial pressure on the structural and optical properties of ZnO film deposited by reactive sputtering," Applied Surface Science, 2007; 253(24): 9414-9421.

6. P. Singh, A. K. Chawla, D. Kaur, and R. Chandra, "Effect of oxygen partial pressure on the structural and optical properties of sputter deposited ZnO nanocrystalline thin films," Materials Letters, 2007, 61(10): 2050-2053. https://doi.org/10.1016/j.matlet.2006.08.013

7. R. K. Gupta, K. Ghosh, S. R. Mishra, and P. K. Kahol, “Opto-electrical properties of Ti-doped In2O3 thin films grown by pulsed laser deposition," Applied Surface Science, 2007; 253(24): 9422-9425. https://doi.org/10.1016/j.apsusc.2007.06.004

8. S. S. Yap, and T. Y. Tou, "Target-plane deposition of diamond-like carbon in pulsed laser ablation of graphite," Applied Surface Science, 2007; 253(24): 9521-9524

9. H. K. Jung, C. K. Seul, and H. K. Do, "Fabrication and Characterization of ZnS/Diamond-Like Carbon Core-Shell Nanowires," Journal of Nanomaterials 2016, Article ID 4726868 doi:10.1155/2016/4726868

10. G. Taher, A. A. Muneera, and L. A. Amal, "Synthesis and Characterization of $\mathrm{ZnO} / \mathrm{ZnS}$ Core/Shell Nanowires," Journal of Nanomaterials 2014, Article ID 989632, doi:10.1155/2014/989632

11. S. Patra, S. Mondal, and P. Mitra, "Preparation of ZnS and SnS Nanopowders by Modified SILAR Technique," Journal of Physical Sciences 2009;13: 229-234.

12. S. Kalyanasundaram, K. Panneerselvam, and V. S. Kumar, "Study on Physical Properties of ZnS Thin Films Prepared by Chemical Bath Deposition," Asia Pacific Journal of Research 2013. ISSN2320-5504

13. M. Dhanam, and B. Kavitha, "Influence of TEA (Complexing Agent) on The Structural Properties of CBD ZnS Thin Films," Chalcogenide Letters 2009; 6(7):299-307.

14. Y. Fei-Peng, O. Sin-Liang, Y. Pin-Chuan, W. Bing-Rui, and W. Dong-Sing, "Structural, Surface Morphology and Optical Properties of ZnS Films by Chemical Bath Deposition at Various Zn/S Molar Ratios," Journal of Nanomaterials 2014, Article ID 594952, doi:10.1155/2014/594952

Published By:

Blue Eyes Intelligence Engineering and Sciences Publication

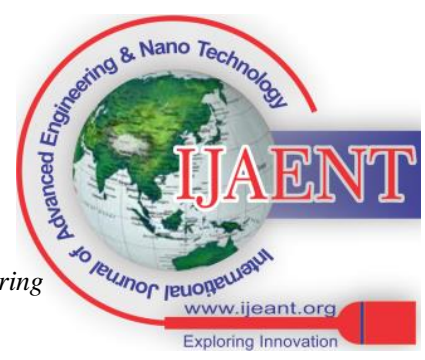


15. S. Thirumavalavan, K. Mani, and S. Sagadevan, "Studies on structural, surface morphology and optical properties of Zinc sulphide (ZnS) thin films prepared by chemical bath deposition," International Journal of Physical Sciences 2015;10(6): 204 - 209.

16. A. Mukherjee, S. Chattopadhyay, and P. Mitra, "Characterization of ZnS Thin Film Synthesised by CBD using Zinc Acetate Precursor' 2015; 20:195-203.

17. T. K. Shih, J. R. Ho, C. F. Chen, W. T. Whang, and C. C. Chen, "Topographic control on silicone surface using chemical oxidisation method," Applied Surface Science, 2007; 253(24): 9381-9386. https://doi.org/10.1016/j.apsusc.2007.05.073

18. N. Shanmugam, S. Cholan, N. Kannadasan, K. Sathishkumar, and G Viruthagiri, "Effect of Annealing on the ZnS Nanocrystals Prepared by Chemical Precipitation Method," Journal of Nanomaterials 2013, doi:10.1155/2013/351798

19. K. Vishwakarma, "Study of Structural and Optical Properties of ZnS Nanoparticles," Asian Journal of Chemistry 2013; 25:S45-S57

20. P. Iranmanesh, S. Saeednia, and M. Nourzpoor, "Characterization of ZnS Nanoparticles Synthesised by Co-Precipitation Method," Chin Phys. B. 2015; 24(4): 046104

21. N. A. A. M. Arif, C. C. Jiun, and S. Shaari, "Effect of Annealing Temperature and Spin Coating Speed on Mn-Doped ZnS Nanocrystals Thin Film by Spin Coating," Journal of Nanomaterials 2017, Article ID 2560436, doi:10.1155/2017/2560436

22. V. Kumar, M. Saroja, M. Venkatachalam, and S. Shankar, "Synthesis and Characterization of ZnS Thin Films by Sol-Gel Dip and Spin Coating Methods," International Journal of Recent Scientific Research 2015; 6(11): 7377-7379.

23. F. Zabihi, Y. Xie, S. Gao, and M. Eslamian, "Morphology, conductivity, and wetting characteristics of PEDOT:PSS thin films deposited by spin and spray coating," Applied Surface Science, 2015; 338: 163-177. https://doi.org/10.1016/j.apsusc.2015.02.128

24. J. Jiang, H. J. Tao, S. Chen, B. Tan, N. Zhou, L. Zhu, and J. Tao, "Efficiency enhancement of perovskite solar cells by fabricating as-prepared film before sequential spin-coating procedure," Applied Surface Science, 2016; 371: 289-295.

25. E. Heredia, C. Bojorge, J. Casanova, H. Cánepa, A. Craievich, and G. Kellermann, "Nanostructured ZnO thin films prepared by sol-gel spin-coating," Applied Surface Science, 2014; 317: 19-25.

26. B. O. Uysal, and U. O. A. Arier, "Structural and optical properties of SnO2 nano films by spin-coating method," Applied Surface Science, 2015; 350: 74-78. https://doi.org/10.1016/j.apsusc.2015.04.023

27. S. Kumar, and R. Tangavel, "Structural and Optical Properties of Na Doped ZnO Nanocrystalline Thin Films Synthesised Using Sol-Gel Spin Coating Technique," J. Sol-Gel Sci Technol 2013; 67: 50-55.

28. S. A. Mahadik, V. Parale, R. S. Vhatkara, D. B. Mahadik, M. S Kavale, P. B. Wagh, and J. Gurav, "Superhydrophobic silica coating by dip coating method," Applied Surface Science, 2013; 277: 67-72.

29. J. Magura, A. Zeleňáková, V. Zeleňák, and M. Kaňuchová, "Thiol-modified gold nanoparticles deposited on silica support using dip coating," Applied Surface Science, 2014; 315(1): 392-399. https://doi.org/10.1016/j.apsusc.2014.07.173

30. S. Li, B. Gao, S. Yin, G. Tu, G. Zhu, S. Sun, and X. Zhu, "The effects of $\mathrm{RE}$ and $\mathrm{Si}$ on the microstructure and corrosion resistance of Zn-6Al-3Mg hot dip coating," Applied Surface Science, 2015; 357: 2004-2012. https://doi.org/10.1016/j.apsusc.2015.09.172

31. U. S. Senapati, D. K. Jha, and D. Sarkar, "Green Synthesis and Characterization of ZnS Nanoparticles," Research Journal of Physical Sciences 2013; 1(7):1-6.

32. T. V. M. Sreekanth, M. J. Jung, and I. Y. Eom, "Green synthesis of silver nanoparticles, decorated on graphene oxide nanosheets and their catalytic activity," Applied Surface Science, 2016; 361: 102-106. https://doi.org/10.1016/j.apsusc.2015.11.146

33. S., T., and D., R. S., "Green synthesis of highly fluorescent carbon quantum dots from sugarcane bagasse pulp," Applied Surface Science, 2016; 390: 435-443. https://doi.org/10.1016/j.apsusc.2016.08.106

34. N. Matinise, X. G. Fuku, K. Kaviyarasu, N. Mayedwa, and M. Maaza, "ZnO nanoparticles via Moringa oleifera green synthesis: Physical properties \& mechanism of formation," Applied Surface Science, 2017; 406: 339-347. https://doi.org/10.1016/j.apsusc.2017.01.219

35. M. M. Uplane, S. H. Mujawar, A. I. Inamdar, P. S. Shinde, A. C Sonavane, and P. S. Patil, "Structural, optical and electrochromic properties of nickel oxide thin films grown from electrodeposited nickel sulphide," Applied Surface Science, 2007; 253(24): 9365-9371.

36. Z. Jianjun, and D. Junhong, "Synthesis and Characterisation of Sphere-Like Nanocrystals by Thermolysis of A New Complex Precursor," Modern Physics Letters B 2010; 24:19, 2091-2099.

37. X. Xia, Z. Ye, G. Yuan, L. Zhu, and B. Zhao, "Rapid synthesis of novel flowerlike $\mathrm{ZnO}$ structures by thermolysis of zinc acetate,"
Applied Surface Science, 2006; 253(2): 909-914. https://doi.org/10.1016/j.apsusc.2006.01.028

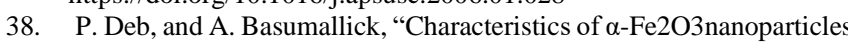
prepared by thermolysis of a nonaqueous precursor," Applied Surface Science, 2001; 182(3-4): 398-402.

39. C. Yu, P. Zhao, G. Chen, and B. Hu, "Al2O3 supported Ru catalysts prepared by thermolysis of Ru3(CO)12 for catalytic wet air oxidation,' Applied Surface Science, 2011; 257(17): 7727-7731.

40. D. R. Do Carmo, L. S. Guinesi, N. L. Dias Filho, and N. R. Stradiotto, "Thermolysis of octa (hydridodimethylsiloxyl) octasilsesquioxane in pyridine media and subsequent toluidine blue $\mathrm{O}$ adsorption," Applied Surface Science, 2004; 235(4): 449-459.

41. B. A. Ezekoye, P. O. Offor, V. A. Ezekoye, and F. I. Ezema, "Chemical Bath Deposition Technique of Thin Films: A Review," International Journal of Scientific Research 2013; (2): 452-456.

42. A. N. Singh, L. R. Singh, S. N. Singh, and S. B. Singh, "Synthesis and Characterisation of ZnS Nanostructured Thin Films," International Journal of Luminescence and Applications 2013 3(1): 64-67.

43. M. Kostoglou, N. Andritsos, and A. J. Karabelas, "Modelling Thin Film CdS Development in a Chemical Bath Deposition Process," Ind. Eng. Chem. Res 2000; 39: 3272-3283.

44. N. A. A. M. Arif, and S. Shaari, "Improving the Production of Self-Assembled ZnS:Mn Nanocrystals through the Modification of Sol Gel - Spin Coating Approaches," Advanced Materials Research 2014; 1024: 23-26

45. A. G. Emslie, F. T. Bonner, and L. G. Peck, "Flow of a Viscous Liquid on a Rotating Disk,” J. Appl. Phys. 1958; 29, 858-862.

46. A. U. Ubale, and D. K. Kulkarni, "Preparation and Study of Thickness Dependent Electrical Characteristics of Zinc Sulfide Thin Films," Bull. Mater. Sci. 2005; 28(1):43-47.

47. K. V. Anand, R. Mohan, R. M. Kumar, M. K. Chinnu, and R. Jayavel, "Structural and Optical Properties of High-Purity Cubic Phase ZnS Nanoparticles Prepared by Thermal Decomposition Route for Optoelectronics Applications," Proc Indian Natn Sci Acad 2013; 79 (3): 395-399.

48. A. Dumbrava, V. Ciupina, and G. Prodan, "Characterization of Zinc Sulfide Nanoparticles by Transmission Electron Microscopy," Proceedings Book 276. Adnan Menderes Univeristy, 4th AACD Congress, 29 Sept-3 Oct 2004.

49. R. Wahab, S. G. Ansari, Y. Kim, M. S. Dhage, H. K. Seo, M. Song, and $\mathrm{H}$. Shin, "Effect on the conversion of ZnS to ZnO Nanoparticles Synthesised by the Sol-Gel Method Using Zinc Acetate and Thiourea," Met. Mater. Inter. 2009; 15 (3): 453-458.

\section{AUTHORS PROFILE}

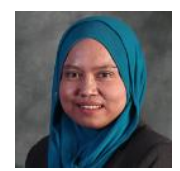

Noor Azie Azura Mohd Arif, received the Bachelor of Engineering in Microelectronics Engineering and Master of Science from Universiti Kebangsaan Malaysia, Postgraduate Diploma (Teaching and Learning) from Universiti Malaysia Sarawak. She started joined Universiti Malaysia Sarawak since January 2011 and present as a lecturer. Her areas of research are developing of $\mathrm{ZnS}$ nanoparticle with spin coating method and modelling of $\mathrm{ZnS}$ nanoparticle by self-assembled approach. Presently, she is pursuing Doctor of Philosophy with Institute of Microengineering and Nanoelectronics (IMEN), Universiti Kebangsaan Malaysia, in the field of fiber optic.

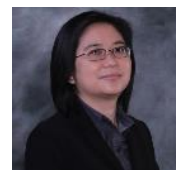

Chin Suk Fun, works as Associate Professor at the Faculty of Resource Science and Technology, Universit Malaysia Sarawak (UNIMAS). She holds a MSc (Environmental Chemistry), PhD (Physical Chemistry, University of Western Australia). Her research interest includes structural chemistry, cellulose nanoparticles, starch nanoparticles, cellulose microspheres, hydrogel, and controlled release fertilizer. She has more than 79 publications of article paper and 27 of research project.

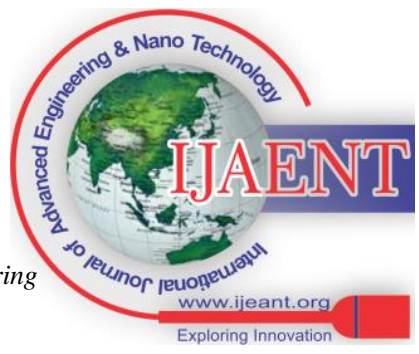

